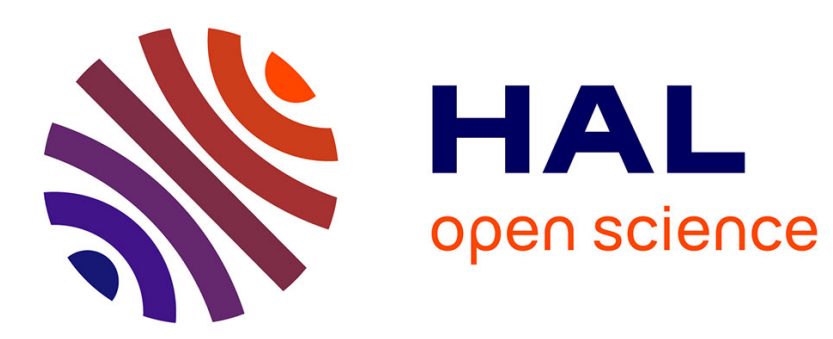

\title{
A Smoke Screen Theory of Financial Intermediation Régis Breton
}

\section{- To cite this version:}

Régis Breton. A Smoke Screen Theory of Financial Intermediation. 2006. halshs-00009595

\section{HAL Id: halshs-00009595 \\ https://shs.hal.science/halshs-00009595}

Preprint submitted on 13 Mar 2006

HAL is a multi-disciplinary open access archive for the deposit and dissemination of scientific research documents, whether they are published or not. The documents may come from teaching and research institutions in France or abroad, or from public or private research centers.
L'archive ouverte pluridisciplinaire HAL, est destinée au dépôt et à la diffusion de documents scientifiques de niveau recherche, publiés ou non, émanant des établissements d'enseignement et de recherche français ou étrangers, des laboratoires publics ou privés. 


\title{
A smoke screen theory of financial intermediation
}

\author{
Régis Breton* \\ CNRS and LEO, University of Orléans.
}

This version: March 10, 2006

INCOMPLETE

\begin{abstract}
This paper analyzes a stylized (two period) credit market where investors care about the appropriability of the information they produce when they engage in costly ex ante evaluation of borrowers quality. We show that diversified intermediation arises as a dissimulation mechanism allowing investors to extract informational rents in the second period, thereby mitigating the underlying appropriability problem.
\end{abstract}

Keywords : financial intermediation, informational rent, asymmetric information, free riding, diversification

JEL Classification : D82, G00, G21

\section{Introduction}

From a general perspective, the costly production of socially valuable information by private agents is undermined by two pervasive problems (Hirshleifer and Riley 1979). The reliability problem arises when an individual cannot credibly pass the information to others, with the consequence that opportunities to sell the information are limited. The appropriability problem arises on the contrary when the individual cannot prevent others from using the information without buying it, leading to a standard free

\footnotetext{
${ }^{*}$ Part of this paper was written while visiting the FMG at the London School of Economics. I am indebted to David Webb for his hospitality. I also wish to thank Michel Aglietta, Jacques Crémer, Bertrand Gobillard, Charles Goodhart, Nobu Kiyotaki, Felix Muennich, Jean-Paul Pollin, JeanCharles Rochet, Laurence Scialom and particularly Vincent Bignon and Antoine Faure-Grimaud for helpful comments. Comments by participants at seminars at University Paris 10 and at the London School of Economics are gratefully aknowledged. Remaining errors are my sole responsability.

${ }^{\dagger}$ E-mail: regis.breton@univ-orleans.fr
} 
riding phenomenon. In both situations, information production is limited because the producer cannot extract the full value of information.

Intermediaries - and other institutions - may have been tailored as a response to those and analogous informational frictions. Specifically, Ramakrishnan and Thakor (1984) and Allen (1990), among others, have shown that financial intermediaries can mitigate the first problem by lowering the cost of signaling information ${ }^{1}$. In contrast, we develop in this paper a theory of financial intermediation as a solution to the second problem. The key idea is that intermediation raises the share of the value of information that is appropriable, because it reduces the leakage of information from the producer of that information to his competitors. The theory therefore provides an explanation for the proprietary nature of the information banks and other financial institutions have about their clients.

More precisely, we analyze a credit market where lenders' main concern is the appropriability of the information they produce when initially engaging in the costly evaluation of loan applicants. This hinges on two ingredients. (a) The present value of information is distributed over two periods but the short term value does not cover the initial cost. (b) The credit granting decision allows outside investors to infer the quality of borrowers, thereby allowing them to poach ex post good borrowers without having paid the initial cost. We show that diversification within a financial intermediary can arise as a solution to this problem. The intuition runs as follows. By simultaneously financing more borrowers - some of which he is not able to evaluatethe intermediary introduces "noise" in his credit decision and can more easily conceal information about the quality of an individual borrower. This gives more incentives to engage in ex ante screening. Diversification therefore acts as a way to protect the informational rent thereby granting the future payments necessary to cover the initial screening cost.

This work obviously relates to the huge literature on relationship banking initiated by Mayer (1988). Our intermediary arises as a way to maintain the privacy of information. In that sense, a contribution of the paper is to provide an explanation for the proprietary aspect an intermediary's information about borrowers. This proprietary nature of banks' information is one determinant of firms' choice of financing sources as argued for instance by Yosha (1995) and Bhattacharya and Chiesa (1995) ${ }^{2}$. This may be contrasted to the idea formalized by Boyd and Prescott (1986) and Ramakrishnan and Thakor (1984) that intermediaries foster the revelation of hidden information.

The paper is more closely related to the literature explaining diversification within intermediaries in a world of risk neutrality. In Diamond's (1984) theory diversification of the bank portfolio reduces delegation costs because in the limit the intermediary's liabilities are certain and independent of the intermediary's private information. In our paper a larger portfolio diminishes the informational leakage about individual borrowers. Cerasi and Daltung (2000) introduce diseconomies of scale in monitoring and show that despite this some diversification raises the bank's incentives to monitor. Like them, we have some notion of diseconomies of scale (in screening) as our

\footnotetext{
${ }^{1}$ These contributions follow a suggestion by Leland and Pyle (1977). See also Diamond (1984) and Boyd and Prescott (1986).

${ }^{2}$ The idea that confidentiality has value in its own right was suggested by Campbell (1979).
} 
intermediary financing projects that he cannot screen. Furthermore, we also show that limited diversification can be beneficial ${ }^{3}$. However our mechanism is very different and their paper focus on explaining the structure (debt financed) and optimal size of banks. In a non banking context, Faure-Grimaud and Inderst (2005) analyze conditions for a conglomerate structure to lower the cost of financing in the optimal contracting framework of Bolton and Scharfstein (1990).

Secondly, this paper relates to the literature on information production in credit markets. Chan, Greenbaum and Thakor (1986) analyze the interplay between the reusability of information about borrowers and lenders' incentives to engage in screening activities. The appropriability problem and related issues are considerer in the context of credit-worthiness tests in Broecker (1990) and Gehrig (1998). The main focuss of those paper is the effect of increased competition on the equilibrium on the credit market. Hauswald and Marquez (2002) study the strategic use of information acquisition as a barrier to entry. The paper that is most related to ours is Anand and Galetovic (2000). In a related framework, they show that the competitive structure of the market endogenously adapts in response to the free-riding problem. We analyze a distinct solution to the same problem. Another closely related paper is Bernhardt and Krasa (2004). They show how the possibility of outside funding affects the contracting terms when an informed financier has more information than the entrepreneur. Their main focus is to explain venture capital finance.

The rest of the paper is organized as follows. In section II the environment is laid out and the social value of information is computed. The equilibria with individual finance and diversified intermediation are solved in section III and section IV. Section $\mathrm{V}$ provides some discussion. An appendix contains some proofs.

\section{The environment}

\section{A. Agents and technology}

We consider a two period economy populated by entrepreneurs (borrowers) and investors. All agents are risk neutral and act to maximize $\mathrm{E}_{t=0}\left[c_{1}+c_{2}\right]$. The riskless rate of interest is normalized to 0 .

Borrowers. There are 2 cashless borrowers, labeled $j=A, B$. Each borrower can be of either high $(\theta=H)$ or low $(\theta=L)$ type. The probability $\lambda$ that a given borrower is of type $H$ is common knowledge. A borrower has access to two successive projects, each one requiring an initial investment of $I_{t}=1$. In a given period, we will refer to the project owned by a type $\theta(\theta=H, L)$ borrower as a type $\theta$ project. In the first period, a project succeeds with probability $p^{\theta}$ in which case it generates a cash flow $\pi_{1}>1$ or fails and yields 0 . A type $H$ project is better in the sense of first order stochastic dominance: $p^{H}>p^{L}$. To simplify the algebra, it will be assumed that ${ }^{4}$ $p^{L}=0$. In the second period, the project of type $L$ borrowers always fail, while those of type $H$ borrowers generate a cash flow $\pi_{2} \equiv 1+\omega>1$ with certainty. For the ease of exposition, we invoke the following restrictions on parameters, the interpretation

\footnotetext{
${ }^{3}$ See also Krasa and Villamil (1992) and Bond (2004) for results about less than perfect diversification.

${ }^{4}$ What matters for the analysis is that a (first period) type $L$ project be socially inefficient. All the results go through as soon as $p^{L} \pi_{1}<1$.
} 
of which will be given momentarily:

$$
\begin{aligned}
\lambda p^{H} \pi_{1} & >1, \\
\lambda\left(1-p^{H}\right)\left(\pi_{2}-1\right) & <1-\lambda .
\end{aligned}
$$

To focuss on the interplay between the production of information and the creation of informational asymmetries, we assume that borrowers do not know their type ${ }^{5}$.

Lenders. There are two types of potential lenders. First, there is a large number of investors with enough endowment to finance one project per period $\left(e_{t}=1\right)$. Secondly, there are two sophisticated lenders - or "specialists" - with the same endowment but with the ability to screen one borrower at date 1. More precisely, say because screening takes time, a sophisticated lender is unable to screen two projects at the same time. To put it differently, screening exhibits decreasing return to scale. Another interpretation of this specification is that a specialist has the ability to evaluate only $A$ or $B$, with private information about which of the two he is able to evaluate. Instead, outsiders think he is able to screen $A$ or $B$ with equal probabilities. This assumption captures the idea that there is some prior (but imperfect) knowledge so as to each investors' specialization.

Screening is costly for the specialist and yields a perfectly informative signal about the borrower's type. The type is then revealed to the specialist and to the borrower. However, the act of screening is not publicly observable, and is therefore non contractible. Most of the analysis will be conducted under the assumption that there only one sophisticated lender, named $\mathrm{S}$, with a screening cost $c$ in utility. In section IV.C, we shall consider the case of two specialists, with heterogenous screening costs, $c$ and $C(c<C)$.

\section{B. Value of information.}

Throughout the paper, we use the expression "value of information" to refer to the social value of screening. This value is computed by comparison with the allocation of credit without screening.

If a borrower's is unknown, the first period project is funded, according to assumption (A1). In period 2, refinancing is contingent on the first period outcome. As all type $L$ project fail, a success in period 1 signals that the borrower is of type $H$, so that his second period project is funded. A borrower whose first period project failed is of type $H$ with probability

$$
\lambda^{\prime} \equiv \operatorname{Pr}[H \mid \text { failure }]=\frac{\lambda\left(1-p^{H}\right)}{\lambda\left(1-p^{H}\right)+1-\lambda} .
$$

Now, (A2) can be rearranged to yield $\lambda^{\prime} \pi_{2}<1$ implying that the second period project of such a borrower has negative NPV, and is not financed.

Knowledge of the type allows to reject low type projects in period 1 and to avoid rejecting high type projects in period 2. The social value of information is therefore

\footnotetext{
${ }^{5}$ Note that this is without loss of generality as borrowers have no collateral available and type $L$ projects allways fail. Assuming that type $L$ borrowers get arbitrarily small payoff from being financed, no menu of contracts allows to separate types. This distinguishes our approach from Bernhardt and Krasa (2004).
} 
distributed over two periods of time and can be decomposed as the sum $v_{1}+v_{2}$ of first period and second period value, with

$$
\begin{aligned}
& v_{1}=1-\lambda, \\
& v_{2}=\lambda\left(1-p^{H}\right)\left(\pi_{2}-1\right) .
\end{aligned}
$$

It will be assumed that screening is socially optimal but that the short term value of information does not cover the screening $\operatorname{cost} c$ :

$$
v_{1}+v_{2}>c>v_{1}
$$

For the ease of exposition, it will be convenient to introduce the following notations for the (gross) social surpluses for a screened and an unscreened project, respectively:

$$
\begin{aligned}
U_{e} & =\lambda\left(p^{H} \pi_{1}-1+\omega\right), \\
U_{n e} & =\lambda p^{H}\left(\pi_{1}+\omega\right)-1 .
\end{aligned}
$$

Naturally, one has $U_{e}-U_{n e}=v_{1}+v_{2}$.

\section{Limited commitment.}

We assume that long term contracts between a lender and a borrower are not feasible. Coupled with assumption (A3), this induces the problem of the appropriability of the information produced by a specialist, because the short term value of information, $v_{1}$, is not sufficient to induce screening. While we take this restriction as exogenous, it could be justified by the incentive effects of short term contract and the introduction of moral hazard considerations (see section $\mathrm{V}$ ).

\section{Timing of events.}

At date 0 , lenders compete for borrowers by offering interest rate $R$ for period 1 . When there is only one specialist with the ability to screen, this implies that $\mathrm{S}$ can extract all the surplus from trade. Borrowers choose an investor to fund their first period project. Once lenders and borrowers matched, lenders perform their screening and may reject negative NPV projects. First period investment are made.

Date 1 . The payoffs of first period projects are realized and publicly observed. Payment $R$ is made in the case of success. The (potentially) informed lender and borrowers bargain according to a generalized Nash solution.

At date 2, payoff of second period projects are realized and shared according to the agreement reached at date 1.

The next sections solve for the equilibrium on the credit market under two distinct cases: financing by individual investors (section III) or by intermediaries with a diversified credit portfolio (section IV). As a general notation, let $s$ be the mixed screening strategy ( $s=$ probability of screening). As screening is not publicly observable, the equilibrium in each case will comprise the market expectations. As contracts offered are public, the anticipated strategy can be a function of $R$. Denote by $s^{a}(R)$ this anticipated strategy. 


\section{Equilibrium with a focused specialist}

This section solves for the equilibrium when the specialist does not raise additional funds and offers to fund with his own endowment one borrower, say, $A$. This provides a benchmark case, and will be useful in introducing the way we solve for the equilibrium.

Note that unsophisticated lenders would require a payment $R^{0}=\frac{1}{\lambda p^{H}}$ to finance a first period project. As $\mathrm{S}$ can extract all the surplus from a borrower, it is then obvious that $R \geq R^{0}$. Indeed, this is necessary for the specialist to create value:

Lemma 1. If $R<R^{0}$ then $S$ does not screen and does not provide finance.

Proof. The argument is by contradiction. If $\lambda p^{H} R<1$ then it is not rational to fund a project without knowing its type. Financing a project therefore perfectly reveals a type $H$, driving to 0 the share of the long term profit that the initial lender is able to obtain. By (A3), $s=0$, and no project is financed.

We proceed in two steps. First, section A displays the informational rent that the initial investor is able to extract in period 2, taking as given expectations $s^{a}(R)$. Second, in section B we study the optimal screening strategy and characterize the equilibrium.

\section{A. Rent extraction in period 2}

In the second period, the rent that the informed lender is able to extract on positive NPV projects depends on his competitors' information. Let $\rho(p)$ denote this rent, with $p$ the probability assessed by outside investors that the borrower is of type $H$. Formally $p \equiv \operatorname{Pr}[H \mid \mathcal{I}]$, with $\mathcal{I}$ the public information at date $t=1$.

To fix ideas, we assume that the informed lender and the borrower bargain over the rent associated with their bilateral relationship. We use a generalized Nash bargaining solution. The borrower's outside option is the surplus he gets if financed by another investor, while the lender's outside option is simply 0 (riskless rate). The bilateral rent is given by $\left(\pi_{2}-1-\left(\pi_{2}-\frac{1}{p}\right)\right)=\frac{1}{p}-1$ when the borrower can get financed outside the relationship (at the rate $\frac{1}{p}$ ) and $\pi_{2}-1$ otherwise. The lender can seek finance outside the relationship only if $p \pi_{2}>1$ or, equivalently if $\frac{1}{p}-1<\omega$. Further assuming that threat points equate outside options and that lender has all the bargaining power one gets ${ }^{6}$

$$
\rho(p)=\min \left\{\frac{1}{p}-1, \omega\right\} .
$$

As prescribed by intuition, the informational rent increases with the investor's informational advantage, measured by $\left(1-\frac{1}{p}\right)$.

Figure 1 summarizes all events for a specialist matched with the borrower he is able to screen. The investor cannot extract any profit in period 2 on borrowers whose first project succeeded as this publicly signals a high type (thus $p=1$ in that

\footnotetext{
${ }^{6}$ Alternatively, one could assume a first price sealed auction between the informed specialist and uniformed competitors, as in Rajan (1992) or von Thadden (2001). Our assumptions are such that Rajan's (1992) proposition 3 applies, yielding (6) as the expected gain of the informed lender.
} 


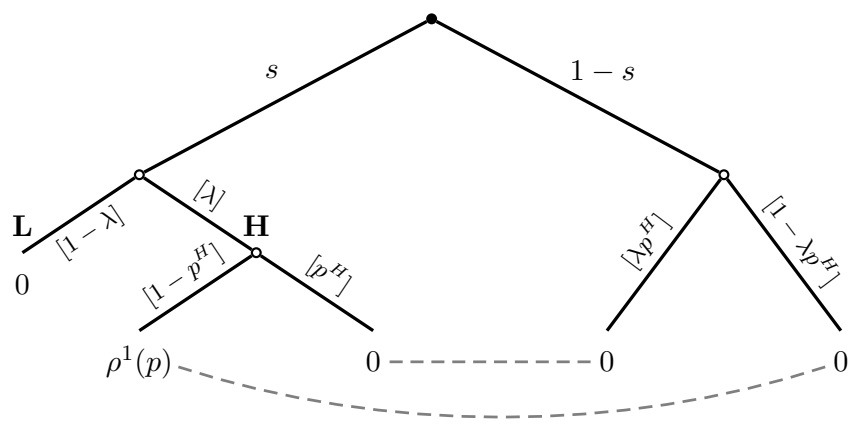

Figure 1: Second period gains for a specialist with mixed strategy $s$. Dashed lines represent the information set of outside investors.

case, implying $\rho(1)=0$ ). The rent that can be extracted on a high type borrower who experienced a failure is a function of outsiders' expectations as to the screening strategy. For an anticipated strategy $s^{a}$, we let $p^{1}\left(s^{a}\right)$ be the probability (of a type $H$ ) assessed by an outside investor after observing that the borrower was financed and that the first project failed. Using Bayes' rule this can be computed as

$p^{1}\left(s^{a}\right)=\frac{s^{a} \lambda\left(1-p_{H}\right)}{s^{a} \lambda\left(1-p_{H}\right)+\left(1-s^{a}\right)\left(1-\lambda p_{H}\right)} \cdot 1+\frac{\left(1-s^{a}\right)\left(1-\lambda p_{H}\right)}{s^{a} \lambda\left(1-p_{H}\right)+\left(1-s^{a}\right)\left(1-\lambda p_{H}\right)} \cdot \lambda^{\prime}$.

Rearranging and using expression $(1), p^{1}\left(s^{a}\right)$ can be expressed using the prior probability corrected from first period failure $\lambda^{\prime}$ :

$$
p^{1}\left(s^{a}\right)=\frac{s^{a} \lambda^{\prime}}{s^{a} \lambda^{\prime}+1-s^{a}} \cdot 1+\frac{1-s^{a}}{s^{a} \lambda^{\prime}+1-s^{a}} \cdot \lambda^{\prime} .
$$

One convenient way to look at Eq. (7) is as the weighted average of the information possessed by an informed investor and by an uninformed one. To see this denote by $\mathcal{I} \in\{h, \varnothing\}$ the information possessed by an informed or uniformed specialist respectively ${ }^{7}$. Then outsiders's assessment of the type can be computed as

$$
p^{1}\left(s^{a}\right)=\operatorname{Pr}[H \mid h] \operatorname{Pr}[h \mid y, f]+\operatorname{Pr}[H \mid \varnothing, f] \operatorname{Pr}[\varnothing \mid y, f] .
$$

Now, the probability of the specialist having superior information about the project's type is (conditional on stage 1 financing):

$$
\operatorname{Pr}[h \mid y, f]=\frac{s^{a} \operatorname{Pr}[H \mid f]}{s^{a} \operatorname{Pr}[H \mid f]+1-s^{a}} .
$$

Plugging (9) in (8) yields formula (7). Expression (7) features the leakage of the specialist's private information to outside investors. This is apparent from the fact that $p^{1}\left(s^{a}\right)>\lambda^{\prime}$ as soon as $s^{a}>0$ : observing the financing of a borrower has informational content. In the case of an anticipated pure strategy $s^{a}=1$, there is complete revelation of the initial lender's information, as $p^{1}(1)=1$.

\footnotetext{
${ }^{7}$ With the obvious notation that $\mathcal{I}=h$ when the specialist knows the borrower to be of the $H$ type and $\mathcal{I}=\varnothing$ when he does not have superior information. As no recognized $L$-project gets financed, the case $\mathcal{I}=l$ can be pruned.
} 


\section{B. Equilibrium characterization}

We first solve for S's screening strategy for given expectations $s^{a}(R)$. In a second step, the equilibrium strategy and expectations are jointly determined.

Consider first the expected gain of the specialist. As $R \geq R^{0}$, S rejects a borrower when he knows he is of type $L$, and provide first period finance otherwise. The expected gain as a function of the screening strategy $s$ writes

$$
\Pi(s, R) \equiv s\left[\lambda\left(p^{H} R-1+\left(1-p^{H}\right) \rho^{1}(R)\right)-c\right]+(1-s)\left[\lambda p^{H} R-1\right],
$$

where $\rho^{1}(R) \equiv \rho \circ p^{1} \circ s^{a}(R)$ denotes the rent extracted in the second period on a type $H$ borrower whose first project failed. From the linearity of profit (10) it follows that the optimal screening decision is given by the "knife-edge" strategy:

$$
s^{*}(R)=\left\{\begin{array}{cc}
0 \\
{[0,1]} \\
1
\end{array} \text { when } \begin{array}{ll}
\lambda\left(1-p^{H}\right) \rho^{1}(R)+(1-\lambda) & <c \\
& >c
\end{array}\right.
$$

We focuss on equilibria where agents' expectations are correct. In equilibrium the anticipated strategy must be correct, so that $s^{*}(R)=s^{a}(R)$.

Using (11) it is easy to solve for the equilibrium. As a first result, one can show that the assumption that the net present value of information is positive but that the short term value falls short of the initial cost implies that there must be some screening in equilibrium $\left(s^{*}>0\right)$ but that optimal screening cannot be attained $\left(s^{*}<1\right)$.

Proposition 1. There is no equilibrium in pure strategies.

Proof. Consider first the candidate equilibrium $s^{*}=1$. Using (11), it must hold that $\lambda\left(1-p^{H}\right) \rho\left(p^{1}(1)\right)+(1-\lambda)>c$. Noting that $\rho\left(p^{1}(1)\right)=\rho(1)=0$, this is equivalent to $v_{1}>c$ which is ruled out by the right hand side of (A3). Consider next the symmetric case $s^{*}=0$. By (11), it must hold that $\lambda\left(1-p^{H}\right) \rho\left(\lambda^{\prime}\right)+(1-\lambda)<c$. But (6) implies $\rho\left(\lambda^{\prime}\right)=\omega$ so that $\lambda\left(1-p^{H}\right) \omega+(1-\lambda)<c$, which is ruled out by the left hand side of (A3).

The intuition for this result is as follows. If outside investors anticipate no screening, the credit granting decision is considered as uninformative. Then the specialist would have an incentive to exert screening as his private information would not be revealed to the market. Conversely, if outside investors anticipate perfect screening then the credit decision would perfectly reveal the outcome of the specialist's screening. Anticipating that outside investors would free ride on his screening activity, the specialist would have no incentives to screen. As a consequence, there must be mixed screening in equilibrium.

A mixed strategy $0<s^{a}<1$ can only be anticipated if investors are indifferent in equilibrium between screening and not screening:

$$
\lambda\left(1-p^{H}\right) \rho \circ p^{1} \circ s^{a}(R)+(1-\lambda)=c
$$

This characterizes the expectations $s^{a}(R)$. Eq (12) simply states that the resulting 


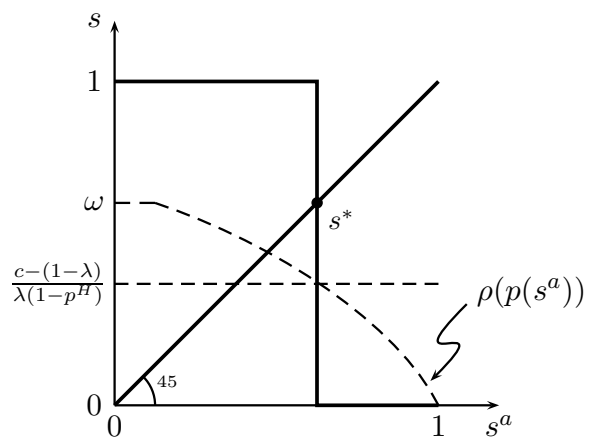

Figure 2: Equilibrium screening $\left(s^{*}=s^{a}\right)$

rent must be such that the private value of information equates the screening cost. (The reasoning is illustrated in figure 2).

One consequence of equation (12) is that in equilibrium expectations as to the screening intensity $s^{a}(R)$ are not affected by the first period payment, $R$. Accordingly, from now on we write the market expectation as $s^{a}$. Using (11) and the fact that $\rho\left(p^{1}\left(s^{a}\right)\right)$ decreases with $s^{a}$ yields the following characterization of the equilibrium:

Proposition 2. The equilibrium is unique and is characterized by a payment $R \geq R^{0}$ and a mixed strategy $0<s_{1}^{*}<1$ such that

$$
\lambda\left(1-p^{H}\right) \rho\left(p^{1}\left(s_{1}^{*}\right)\right)+(1-\lambda)=c
$$

Proof. Obvious.

Define $p^{*}$ as the unique solution to

$$
\lambda\left(1-p^{H}\right) \rho\left(p^{*}\right)+1-\lambda=c
$$

This is the level of outsiders' assessment of the quality of a specialist's project for which the rent is just sufficient to cover the screening cost. Using expression (6) and equation (14), straightforward computations yield the following corollary of proposition 2 (proof in the appendix):

Corollary 3. The equilibrium level of screening for a specialist financing one borrower is given by

$$
s_{1}=\frac{1}{p^{*}} \frac{p^{*}-\lambda^{\prime}}{1-\lambda^{\prime}}
$$

The result in proposition 2 can be interpreted as follows. For information production to take place in equilibrium, the specialist' decision in period 1 must not be fully revealing. In equilibrium, the noise introduced by mixed screening provides a partial solution to the tradeof between the production and the revelation of information. This may be related to Grossman and Stiglitz's (1980) paradox, and to the solution in Kyle (1985).

For the ease of exposition, we have assume that the lender, S, extracts all the surplus from trade. As the equilibrium level of screening is independent of the specialist' profit, this simplification is inconsequential for the analysis of the efficiency of the credit market. 


\section{Equilibrium with a diversified intermediary}

This section shows that the lender who perform the evaluation can retain more of his informational advantage by forming a financial intermediary. Specifically, we show that by attracting simultaneously $A$ and $B, \mathrm{~S}$ can conceal his information, and thereby have more incentives to screen at date 0 . The formation of an intermediary means that the specialist collects the endowment of some other investor and act as a delegated screener.

Given that $\mathrm{S}$ cannot screen both borrowers, we consider that he screens $A$. Define $s$ as the probability of screening, and $s^{a}$ the associated expectations by outside investors.

\section{A. Leakage of information}

First, we will study the leakage of information and show that diversification result in more private information to be retained for a given level of market expectations. Again, $R \geq R^{0}$ must hold in equilibrium, so that an unscreened project is financed in the first period.

Now, depending on the result of S's screening strategy, three cases might arise.

- with probability $1-s$, he does not have any information about $A$ 's type, in which case he finances both borrowers in the first period.

- w.p. $s \lambda$, he learns that $A$ is a type $H$ borrower, and finances both borrowers.

- w.p. $s(1-\lambda)$, he learns that $A$ is a type $L$. In that case, the screened borrower is denied credit and only one borrower (that is, $B$ ) is financed in the first period.

As before, no rent is extracted on borrowers whose first project succeeds. Note that rejection of one borrower in the first period then reveals that he is a low type and that the specialist has no information as to the other's type. We are left with the cases where $\mathrm{S}$ funds both borrowers. Under the maintained assumption that first period profits are observable the leakage of information - for a failed project - when outside investors anticipate a screening strategy $s^{a}$ depends on whether one or two project failed. Let $p_{f f}^{2}\left(s^{a}\right)$ be the assessment on a failed project when both failed, and $p_{s f}^{2}\left(s^{a}\right)$ the assessment when the second project succeeded. Taking into account the relevant probabilities and conditioning on first period failure, we get:

$$
\begin{aligned}
p_{f f}^{2}\left(s^{a}\right) & =\frac{s \lambda^{\prime}}{s \lambda^{\prime}+1-s} \frac{1+\lambda^{\prime}}{2}+\frac{1-s}{s \lambda^{\prime}+1-s} \lambda^{\prime}, \\
& =\lambda^{\prime}+\frac{s \lambda^{\prime}}{s \lambda^{\prime}+1-s} \cdot \frac{1-\lambda^{\prime}}{2} .
\end{aligned}
$$

and

$$
\begin{aligned}
p_{s f}^{2}\left(s^{a}\right) & =\frac{s \lambda^{\prime}}{s \lambda^{\prime}+s+2(1-s)} 1+\frac{s}{\cdots+\cdots+\cdots} \lambda^{\prime}+\frac{2(1-s)}{\cdots+\cdots+\cdots} \lambda^{\prime}, \\
& =\lambda^{\prime}+\frac{s\left(1-\lambda^{\prime}\right)}{s \lambda^{\prime}+2-s} \lambda^{\prime}
\end{aligned}
$$


S's initial credit decision does reveal some information to the market as both probabilities are greater than the unconditional probability, $\lambda^{\prime}$. However for given market expectations there is less leakage of information than in the case of the individual investor. Indeed the comparison of (17), (19) and (7) shows that

$$
p_{s f}^{2}\left(s^{a}\right)<p_{f f}^{2}\left(s^{a}\right)<p^{1}\left(s^{a}\right) \quad \forall s>0 .
$$

In particular, note that $p_{f f}^{2}(1)<1$, so that a specialist screening with probability one retains private information as to the borrower's type.

\section{B. Equilibrium screening}

We now compute the screening strategy, taking market beliefs, $s^{a}$, as given. What matters for S's decision is the information inferred by the market from his financing decision, viz. $p_{s f}^{2}$ and $p_{f f}^{2}$.

The screening intensity is chosen so as to maximize $\Pi_{2}(s, R)-s c$, where

$$
\begin{aligned}
\Pi_{2}(s, R) & \equiv(1-s)\left[2\left(\lambda p_{h} R-1\right)\right]+s(1-\lambda)\left[\lambda p_{h} R-1\right] \\
& +s \lambda\left[p_{h} R-1+\lambda p_{h} R-1+\left(1-p_{H}\right)\left(\lambda p_{h} \rho\left(p_{s f}^{2}\right)+\left(1-\lambda p_{H}\right) \rho\left(p_{f f}^{2}\right)\right)\right] .
\end{aligned}
$$

The expected gain for the specialist can be simplified as

$$
\Pi_{2}(s, R)=s(1-\lambda)+s \lambda\left(1-p_{H}\right)\left(\lambda p_{h} \rho\left(p_{s f}^{2}\right)+\left(1-\lambda p_{H}\right) \rho\left(p_{f f}^{2}\right)\right) .
$$

The analysis of the equilibrium is analogous to that in section III with the exception of the substitution of the expected rent $\left[\lambda p_{h} \rho\left(p_{s f}^{2}\right)+\left(1-\lambda p_{H}\right) \rho\left(p_{f f}^{2}\right)\right]$ for $\rho\left(p^{1}\left(s^{a}\right)\right)$. The same argument can be applied to show that there must be some evaluation in equilibrium. However, there are now cases where the equilibrium screening strategy is $s^{*}=1$ if the extracted rent is sufficient. Specifically, $s^{*}=1$ if the following condition holds:

$$
1-\lambda+\lambda\left(1-p_{H}\right)\left(\lambda p_{h} \rho\left(p_{s f}^{2}(1)\right)+\left(1-\lambda p_{H}\right) \rho\left(p_{f f}^{2}(1)\right)\right)>c .
$$

Using (17) and (19) the above condition can be rewritten as

$$
1-\lambda+\lambda\left(1-p_{H}\right)\left(\lambda p_{h} \frac{2}{1+\lambda^{\prime}}+\frac{1}{2}\left(1-\lambda p_{H}\right) \frac{\lambda^{\prime}+1}{\lambda^{\prime}}-1\right)>c .
$$

We therefore have the following characterization.

Proposition 4. There exists a unique equilibrium with (i) $s_{2}^{*}=1$ if condition (23) holds, and (ii) $0<s_{2}^{*}<1$ otherwise, with

$$
\lambda\left(1-p^{H}\right) \rho\left(\lambda p_{h} \rho\left(p_{2}^{s f}\left(s_{2}^{*}\right)\right)+\left(1-\lambda p_{H}\right) \rho\left(p_{f f}^{2}\left(s_{2}^{*}\right)\right)\right)+(1-\lambda)=c
$$

Proof. Follows from the monotonicity of $p_{2}^{s f}\left(s_{2}^{*}\right)$ and $p_{f f}^{2}\left(s_{2}^{*}\right)$.

The intuition behind this result is as follows. The left hand side of (22) is the maximum private value of screening for the specialist. Now, the specialist's optimal strategy is still given by the first order condition (11) with the obvious substitution for $\rho\left(p^{1}\left(s^{a}\right)\right)$. By a reasoning similar to that of section $\mathrm{B}$ one has $0<s_{2}^{*}<1$ in so far as condition (23) does not hold.

As diversification entails less leakage of information, the equilibrium screening strategy is characterized by more screening: 
Proposition 5. In equilibrium, it holds that $s_{2}^{*}(c)>s_{1}^{*}(c)$.

Proof. Assume the contrary. From propositions 2 and $4, s_{1}^{*}$ and $s_{2}^{*}$ satisfy

$$
\lambda p_{h} \rho\left(p_{s f}^{2}\left(s_{2}^{*}\right)\right)+\left(1-\lambda p_{H}\right) \rho\left(p_{f f}^{2}\left(s_{2}^{*}\right)\right)=\rho\left(p^{1}\left(s_{1}^{*}\right)\right) .
$$

From $s_{2}^{*} \leq s_{1}^{*}$ and the monotonicity of $p_{s f}^{2}($.$) and p_{f f}^{2}($.$) , we have p_{s f}^{2}\left(s_{2}^{*}\right) \leq p_{s f}^{2}\left(s_{1}^{*}\right)$ and $p_{f f}^{2}\left(s_{2}^{*}\right) \leq p_{f f}^{2}\left(s_{1}^{*}\right)$, so that $(25)$ implies

$$
\lambda p_{h} \rho\left(p_{s f}^{2}\left(s_{1}^{*}\right)\right)+\left(1-\lambda p_{H}\right) \rho\left(p_{f f}^{2}\left(s_{1}^{*}\right)\right)=\rho\left(p^{1}\left(s_{1}^{*}\right)\right) .
$$

Now, $p_{s f}^{2}\left(s_{1}^{*}\right)<p_{f f}^{2}\left(s_{1}^{*}\right)<p^{1}\left(s_{1}^{*}\right)$ from $(20)$ and $s_{1}^{*}<1$. As $\rho($.$) is decreasing, (26)$ cannot hold.

This result has a simple intuition. A larger portfolio allows the specialist to commit to screen more because outside investors are unsure about which borrower is being screened.

To conclude, we need to show that $\mathrm{S}$ can obtain additional funds from an unsophisticated investor to finance two projects. This easily follows from the fact that the equilibrium payment is at least $R_{0}$. Offering a payment $R_{0}$ if one first period project succeeds is (more than) sufficient to give the investor a non negative expected first period rate of return. Consequently, the problem between the intermediary and his borrowers does not exist between the intermediary and his lender. There is no need to "monitor the monitor".

\section{When is intermediation best}

Proposition (5) asserts that diversification raises the incentives to screen when the specialist is able to perform the evaluation of one of the borrowers he attracts. However, this may be costly if the second borrower can be screened by another sophisticated investor.

To analyze this issue, we now consider that there are two heterogenous specialists: $\mathrm{S}$, with a screening cost $c$, and $\mathrm{T}$, with a screening cost $C>c$. We maintain the assumption that $v_{1}<c<v_{1}+v_{2}$. We show that even if $\mathrm{S}$ does not screen one of the borrowers - who could have been screened by $\mathrm{T}$ - it may be optimal to have $\mathrm{S}$ financing both borrowers.

Consider first the case in which each specialist finances one borrower. From section III we know that the specialists' screening intensities depend on their respective costs. The expected surplus is

$$
\left[s^{1}(c)\left(U_{e}-c\right)+\left(1-s^{1}(c)\right) U_{n e}\right]+\left[s^{1}(C)\left(U_{e}-C\right)+\left(1-s^{1}(C)\right) U_{n e}\right],
$$

whereas if S finances both borrowers the expected surplus is given by

$$
\left[s^{2}(c)\left(U_{e}-c\right)+\left(1-s^{2}(c)\right) U_{n e}\right]+U_{n e} .
$$

Comparing (27) and (28) yields the following condition for intermediation to be best:

$$
\left[s^{2}(c)-s^{1}(c)\right]\left(v_{1}+v_{2}-c\right)>s^{1}(C)\left[v_{1}+v_{2}-C\right]
$$


The left hand side of (29) is the gain in S's screening intensity on the first borrower resulting from the dissimulation effect of diversification. The right hand side is the loss associated with not screening the second borrower.

Proposition 6. Fix $\lambda, p_{H}, \pi_{1}, \pi_{2}$, and c. Then there exists a (unique) threshold $C^{*}>c$ such that intermediation is best for $C>C^{*}$, and specialized finance is best for $C^{*}>C>c$.

Proof. Follows from the monotonicity of the R.H.S. of (29) and the cases $C=c$ and $C \rightarrow v_{1}+v_{2}$.

Proposition shows that even if $\mathrm{S}$ is not the best screener for the second borrower, the gain in screening one borrower may more than offset the cost.

\section{Discussion and extensions}

\section{A. Contractual restrictions}

An important assumption for the analysis is that short term contracts between a borrower and a lender are enforceable, but that long term contracts are not. We view this as a stark way to capture the more general assumption that contractual possibilities are not sufficient to solve the problem of the appropriability of information. When this is the case, diversification within an intermediary provides an additional way to mitigate that problem.

The fact that long term debt contracts are not feasible may be rationalized by the inalienability of human capital ${ }^{8}$. Somewhat relatedly, one can think of the entrepreneur's projects as non contractible "ideas". Alternatively, short term debt may be preferred to long term debt because the threat of termination is used to strengthen borrowers' incentives say, to avoid moral hazard as in Stiglitz and Weiss (1983), or to induce repayment when profits are non verifiable as in Bolton and Scharfstein (1990).

\section{B. Informational content of financing decisions}

In this section, we discuss the timing of the flow of information from the information producer to the market, and we argue that it is consistent with the empirical literature on the impact of credit announcement decision on a firm's share price.

In our framework, the informational content of an initial credit granting is naturally defined as the difference between the probability of a borrower being of a high type conditional on obtaining a credit and the unconditional probability. The former for the case of an information producer with one or two projects, respectively, is easily computed as

$$
\operatorname{Pr}[H \mid \text { loan }]=\frac{s_{1}^{*} \lambda}{s_{1}^{*} \lambda+1-s_{1}^{*}} \cdot 1+\frac{1-s_{1}^{*}}{s_{1}^{*} \lambda+1-s_{1}^{*}} \cdot \lambda,
$$

and

$$
\operatorname{Pr}[H \mid \text { loan }]=s_{2}^{*} \lambda \cdot \frac{1+\lambda}{2}+\left(1-s_{2}^{*} \lambda\right) \cdot \lambda .
$$

\footnotetext{
${ }^{8}$ Consider the following situation. The investor contracts with a firm, but the firm's prospects depend on the ability of some key employees. While long term contracts between the investor and the firm are feasible, employees can leave the firm at the interim stage and set up their own business or be hired by another firm in the same industry.
} 
The informational content of a loan renewal decision is analogously defined as the change in the market assessment of a type $H$ induced by refinancing. Obviously we have for both cases

$$
\lambda=\operatorname{Pr}[H]<\operatorname{Pr}[H \mid \text { loan }]<\operatorname{Pr}[H \mid \text { loan renewal }]=1,
$$

which asserts that in equilibrium the information produced by $\mathrm{S}$ is revealed progressively to the market.

To be precise, eq. (32) implies that initial funding and refunding are both informative. This pattern is consistent with the evidence of a positive impact of bank loans agreement - as opposed to other types of loans - on a borrower's equity price, as first documented on US data by James (1987). Lummer and McConnel (1989) find that only loan renewals have a statistically significant impact. Further studies have qualified this sharp contrast, showing that both new loans and renewed loans are interpreted as good news by the stock market (see for instance Aintablian and Gordon (2000) on Canadian data) ${ }^{9}$. Billet, Flannery and Garfinkel (1995) provide evidence that the market reaction is positively related to the lender's quality, as measured by Moody's rating. The model is consistent with this finding, if we interpret a "better" lender as one with a lower cost of screening, $c$. A decrease in $c$ raises the equilibrium level of screening, $s_{1}^{*}($.$) or s_{2}^{*}($.$) , and (from eq. (30) and (31)) the overall$ informativeness of a funding decision.

We are by no means the first to provide a theoretical model consistent with these empirical finding (see for instance Diamond (1991)). However, the finding that loan renewals convey information to outside investors is generally interpreted as evidence that the initial lender obtains proprietary information over the course of the relationship (Rajan 1992, Petersen and Rajan 1995). We show that this need not be the case. Rather, in the model this is a consequence of the lender's strategy to maintain his information private.

\section{Specialization and diversification}

To be completed.

\section{Concluding remarks}

This paper has presented a model of a financial intermediary as an institution designed to protect informational rents. While the exact mechanism we have outlined is of interest, the broader message of the paper is that information producers in credit markets might find it necessary to develop strategies to keep information private. We believe that this insight could be used to analyze other ways to protect informational rents. For instance, legal systems - via e.g. accounting standards - could be thought of as legal protection of informational rents (as patent policy for innovation). This could be used to explain the empirical link between the stringency of disclosure requirements by firms and the orientation of the financial system (Demirgüç-Kunt and Levine 1996).

\footnotetext{
${ }^{9}$ For a comprehensive survey of that strand of literature, see James and Smith (2000).
} 
Another extension relates to the introduction of liquidity needs. In our model, efficiency requires that the initial lender keeps his information private. This creates a potential lemon problem that impinges on the liquidity of his assets (Akerlof 1970). The resulting tradeoff could be used for instance in the theory of last resort lending. If informational rent extraction is necessary for the production of information, then banks' privileged access to central bank lending could be used to explain their advantage in granting credits. Likewise, this tradeoff could be applied to the venture capital industry to analyst the dynamic evolution from initial concern to maintain some proprietary information to that of revealing firm's quality in order to liquidate one's position.

\section{A. Proof of corrolary 3 .}

We first compute $p^{*}$ as the solution to equation (14). Using expression (6) and proposition 1 one has

$$
\lambda\left(1-p^{H}\right) \frac{1-p}{p}+1-\lambda=c
$$

from where it follows that

$$
p^{*} \equiv \frac{\lambda\left(1-p^{H}\right)}{c+\lambda-1+\lambda\left(1-p^{H}\right)}
$$

One need to find $s_{1}$ such that $p^{1}\left(s_{1}\right)=p^{*}$.Using expression $(7)$ and solving for $s_{1}$ yields formula (15).

\section{B. A few computations}

This section provides some computations for $p^{1}(),. p_{f f}^{2}($.$) and p_{s f}^{2}($.$) . We drop$ the superscript "a" to simplify. To obtain (16)-(17), we first take into account the probabilities of failure of each project for each state of S's information - that is, $(h, \varnothing)$ and $(\varnothing, \varnothing)$ - to get

$$
p_{f f}^{2}(s)=\frac{s \lambda\left(1-p_{H}\right)\left(1-\lambda p_{H}\right)}{\cdots+\cdots} \frac{1+\lambda^{\prime}}{2}+\frac{(1-s)\left(1-\lambda p_{H}\right)\left(1-\lambda p_{H}\right)}{\cdots+\cdots} \lambda^{\prime} .
$$

Dividing above and below by $\left(1-\lambda p_{H}\right)^{2}$ yields

$$
\begin{aligned}
p_{f f}^{2}(s) & =\frac{s \lambda^{\prime}}{s \lambda^{\prime}+1-s} \frac{1+\lambda^{\prime}}{2}+\frac{1-s}{s \lambda^{\prime}+1-s} \lambda^{\prime}, \\
& =\lambda^{\prime}+\frac{s \lambda^{\prime}}{s \lambda^{\prime}+1-s} \cdot \frac{1-\lambda^{\prime}}{2} .
\end{aligned}
$$

Expressions (18)-(19) are obtained similarly:

$$
\begin{aligned}
p_{s f}^{2}(s) & =\frac{s \lambda\left(1-p_{H}\right) \lambda p_{H}}{\cdots+\cdots+\cdots} 1+\frac{s \lambda p_{H}\left(1-\lambda p_{H}\right)}{\cdots+\cdots+\cdots} \lambda^{\prime}+\frac{(1-s) 2 \lambda p_{H}\left(1-\lambda p_{H}\right)}{\cdots+\cdots+\cdots} \lambda^{\prime}, \\
& =\frac{s \lambda^{\prime}}{\cdots+\cdots+\cdots} 1+\frac{s}{\cdots+\cdots+\cdots} \lambda^{\prime}+\frac{2(1-s)}{\cdots+\cdots+\cdots} \lambda^{\prime} \\
& =\frac{s \lambda^{\prime}}{\cdots+\cdots} 1+\frac{2-s}{\cdots+\cdots} \lambda^{\prime}=\lambda^{\prime}+\frac{s\left(1-\lambda^{\prime}\right)}{s \lambda^{\prime}+2-s} \lambda^{\prime}
\end{aligned}
$$


Now, rearranging (7) one gets

$$
p^{1}(s)=\lambda^{\prime} \frac{1}{s \lambda^{\prime}+1-s}=\lambda^{\prime}+\frac{s \lambda^{\prime}}{s \lambda^{\prime}+1-s}\left(1-\lambda^{\prime}\right) .
$$

It is straightforward to check that $p^{1}(),. p_{f f}^{2}($.$) and p_{s f}^{2}($.$) are strictly increasing$ functions. Direct inspection of (36) and (40) shows that $p_{2}^{f f}(s)<p^{1}(s) \quad \forall s>0$. Finally $p_{s f}^{2}(s)<p_{2}^{f f}(s)$ as from (36) and (39) we have

$$
p_{2}^{s f}<p_{2}^{f f} \Longleftrightarrow s \lambda^{\prime}+2-s>2\left(s \lambda^{\prime}+1-s\right) \Longleftrightarrow 0>s\left(\lambda^{\prime}-1\right) .
$$

\section{References}

Aintablian, S. and S. R. Gordon (2000), 'A note on market response to corporate loan announcements in canada', Journal of Banking and Finance 24, 381-393.

Akerlof, G.A. (1970), 'The market for lemons: qualitative uncertainty and the market mechanism', Quarterly Journal of Economics 84, 488-500.

Allen, F. (1990), 'The market for information and the origin of financial intermediation', Journal of Financial Intermediation 1, 3-30.

Anand, B. N. and A. Galetovic (2000), 'Information, nonexcludability, and financial market structure', Journal of Business 73(3), 357-402.

Bernhardt, D. and S. Krasa (2004), 'Informed finance?'. mimeo.

Bhattacharya, S. and G. Chiesa (1995), 'Proprietary information, financial intermediation and research incentives', Journal of Financial Intermediation 4, 328-357.

Billet, M. T., M. J. Flannery and J. A. Garfinkel (1995), 'The effect of lender identity on a borrowing firm's equity return', Journal of Finance 50, 699-718.

Bolton, P. and D. S. Scharfstein (1990), 'A theory of predation based on agency problems in financial contracting', American Economic Review 80(1), 93-106.

Bond, P. (2004), 'Bank and non-bank financial intermediation', Journal of Finance $\mathbf{5 9}(6)$.

Boyd, J. H. and E. C. Prescott (1986), 'Financial intermediaty-coalitions', Journal of Economic Theory 38, 211-232.

Broecker, T. (1990), 'Credit-worthiness tests and interbank competition', Econometrica 58, 429-452.

Campbell, T. S. (1979), 'Optimal investment financing decision and the value of confidentiality', Journal of Financial and Quantitative Analysis 14(5), 913-924.

Cerasi, V. and S. Daltung (2000), 'The optimal size of a bank: Costs and benefits of diversification', European Economic Review 44, 1701-1726.

Chan, Y. S., S. Greenbaum and A. Thakor (1986), 'Information reusability, competition and bank asset quality', Journal of Banking and Finance 10, 243-253. 
Demirgüç-Kunt, A. and R. Levine (1996), 'Stock market development and financial intermediaries: Stylized facts', World Bank Economic Review 10(2), 291-322.

Diamond, D. W. (1984), 'Financial intermediation and delegated monitoring', Review of Economic Studies 51, 393-414.

Diamond, D. W. (1991), 'Monitoring and reputation: The choice between bank loans and directly placed debt', Journal of Political Economy 99(4), 689-721.

Faure-Grimaud, A. and R. Inderst (2005), 'Conglomerate entrenchment under optimal financial contracting', American Economic Review 95(3), 850-861.

Gehrig, T. (1998), 'Screening, cross-border banking, and the allocation of credit', Research in Economics 52, 387-409.

Grossman, S.J. and J.E. Stiglitz (1980), 'On the impossibility of informationally efficient markets', American Economic Review 70, 393-417.

Hauswald, R. and R. Marquez (2002), 'Competition and strategic information acquisition in credit markets'. mimeo.

Hirshleifer, J. and J. G. Riley (1979), 'The analytics of uncertainty and information: An expository survey', Journal of Economic Literature 17, 1375-1421.

James, C. (1987), 'Some evidence on the uniqueness of bank loans', Journal of Financial Economics 19, 217-235.

James, C. and D. C. Smith (2000), 'Are bank still special? new evidence on their role in the corporate capital-raising process', Journal of Applied Corporate Finance 13, 395-422.

Krasa, S. and A. Villamil (1992), 'Monitoring the monitor: An incentive structure for a financial intermediary', Journal of Economic Theory 57, 197-221.

Kyle, A. S. (1985), 'Continuous auctions and insider trading', Econometrica 53, 13151336.

Leland, H. and D. Pyle (1977), 'Information asymmetries, financial structures, and financial intermediation', Journal of Finance 32, 371-388.

Lummer, S. and J. McConnel (1989), 'Further evidence on the bank lending process and the reaction of the capital market to bank loan agreements', Journal of Financial Economics 25, 22-122.

Mayer, C. (1988), 'New issues in corporate finance', European Economic Review 32, 1167-1188.

Petersen, M. A. and R. G.. Rajan (1995), 'The effect of credit market competition on lending relationships', Quarterly Journal of Economics 110, 407-443.

Rajan, R. G. (1992), 'Insiders and outsiders: The choice between informed and arm'slength debt', Journal of Finance 47(4), 1367-1400. 
Ramakrishnan, R. T. and A. V. Thakor (1984), 'Information reliability in a theory of financial intermediation', Review of Economic Studies 51, 415-432.

Stiglitz, J. E. and A. Weiss (1983), 'Incentive effects of terminations: applications to the credit and labor markets', American Economic Review 73(5), 912-927.

von Thadden, E.-L. (2001), 'Asymmetric information, bank lending and implicit contracts: The winner's curse', Journal of Finance $\mathbf{5 6 .}$

Yosha, O. (1995), 'Information disclosure costs and the choice of financing source', Journal of Financial Intermediation 4, 3-20. 